\title{
Assessing aspectual asymmetries in human language processing
}

Foong Ha Yap, Stella Wing Man Kwan, Emily Sze Man Yiu, Patrick Chun Kau Chu and Stella Fat Wong

Department of Linguistics, Chinese University of Hong Kong, China

https://doi.org/10.36505/ExLing-2006/01/0058/000058

\begin{abstract}
This paper reports reaction time studies on aspect processing, and highlights that aspectual asymmetries (perfective vs. imperfective facilitation) in terms of reaction time is dependent on verb types.
\end{abstract}

\section{Introduction}

Human mind constructs mental models of events and situations that unfold in the world around us. Previous studies indicate that various cues contribute to the dynamic representation of these mental models. Madden and Zwaan (2003) have shown that, with respect to accomplishment verbs, perfective sentences (e.g. He lit a fire) are processed faster than imperfective sentences (e.g. He was lighting a fire). This perfective advantage was also found in a number of East Asian languages - e.g. Cantonese (Chan et al., 2004) and Japanese (Yap et al., in press). In this paper we report a series of reaction time studies that investigate the effect of both grammatical aspect and lexical aspect on language processing (see Yap et al., 2006 and Wong, 2006 for detailed discussions). We further discuss issues of interests that have implications for our understanding of cognitive processing.

\section{Definition of aspect}

Grammatical aspect allows us to view a situation as temporally bounded or un-bounded (i.e. with or without endpoint focus). More specifically, perfective aspect allows us to view the event as a whole ('bounded' perspective), while imperfective aspect allows us to focus on the internal stages of an event ('unbounded' perspective) (Comrie 1976). Lexical aspect refers to the situation type denoted by the verb (predicate). Each situation type is distinguished on the basis of temporal features such as dynamism, durativity and telicity. Vendler (1967) identifies four basic situation types: states (e.g. know), activities (e.g. run), accomplishments (e.g. run a mile) and achievements (e.g. break). Smith (1991) includes a fifth category: semelfactives (e.g. cough, iteratively). The present study compares the processing times of two types of grammatical aspect markers (perfectives vs. imperfectives) on two situation types or lexical aspect categories (accomplishments vs. activities).

ExLing 2006: Proceedings of 1st Tutorial and Research Workshop on Experimental Linguistics, 28-30 August 2006, Athens, Greece 


\section{Methodology}

Forced-choice utterance-and-picture matching tasks were used. For each test item, participants first heard a Cantonese utterance with a perfective aspect marker (zo2) or an imperfective aspect marker (gan2). They then immediately were shown a pair of pictures, one picture depicting a completed event and the other depicting an ongoing event. The participants then had to match which picture best describes the utterance they had just heard by pressing the corresponding key on the keyboard (the letter A for the picture on the left and the numeral 5 for the picture on the right). The participants' reaction times were recorded using millisecond INQUISIT software. The ISI between the onset of stimulus and target was $2200 \mathrm{~ms}$. Each picture remained on the screen for a maximum of 3 seconds. Only correctly matched responses completed within 3 seconds were analyzed. A perfective utterance and completed picture pairing constitutes a matched perfective response; an imperfective utterance and ongoing picture pairing constitutes a matched imperfective response. The reaction times for matched perfectives and matched imperfectives were compared using a ANOVAs.

The first part of this experiment involved a simple pair-wise design. This design was used to compare the reaction times of perfective vs. imperfective utterances in contexts involving only one situation type (accomplishments only or activities only). There were 20 test items; plus 8 trial items for the practice session at the beginning of the experiment. All stimuli were counterbalanced. The subjects $(\mathrm{N}=18)$ were native Cantonese speakers (mean age approximately 18$)$.

The second part of the experiment involved a more complex $2 \times 2$ design. This design examined the reaction times of perfective vs. imperfective utterances across two situation types (accomplishments and activities). Hence it tested for potential interaction effects between grammatical aspect and lexical aspect. For this more complex design, there were 24 test items and 8 trial items. The subjects $(\mathrm{N}=32)$ were native speakers of Cantonese (also mean age approximately 18).

\section{Results}

\section{Pair-wise design (accomplishment verbs vs. activity verbs)}

In the pair-wise design, there was evidence of perfective advantage with accomplishment verbs, consistent with earlier findings. The effect of grammatical aspect was significant $(p=.001)$. Perfective $z o 2$ utterances (mean $=941 \mathrm{~ms}, \mathrm{SD}=242$ ) were processed significantly faster than imperfective gan 2 utterances (mean $=1032 \mathrm{~ms}$, $\mathrm{SD}=289$ ). However, with activity verbs, the direction of aspectual asymmetry was reversed, with results showing imperfective facilitation instead. Imperfective gan2 utterances (mean $=1125 \mathrm{~ms}, \mathrm{SD}=367$ ) were processed significantly faster than perfective $z o 2$ utterances (mean $=1211 \mathrm{~ms}, \mathrm{SD}=379$ ). The effect of grammatical aspect was significant $(p=.025)$. 
Assessing aspectual asymmetries in human language processing $\quad 259$

Crucially, the combined results indicate that the perfective advantage observed for accomplishment verbs in earlier studies is not generalizable to all verb types. In particular, there is evidence of strong imperfective facilitation for activity verbs. Table 1 highlights the observed aspectual asymmetries.

Table 1. Aspectual asymmetries across verb types (based on Yap et al., 2006)

\begin{tabular}{|c|c|c|c|c|c|}
\hline Experiment & Verb class & $\begin{array}{l}\text { Perfective } \\
\text { zo2 }\end{array}$ & $\begin{array}{l}\text { Imperfective } \\
\text { gan2 }\end{array}$ & $\begin{array}{l}\mathrm{p}- \\
\text { value }\end{array}$ & $\begin{array}{l}\text { Aspectual } \\
\text { facilitation }\end{array}$ \\
\hline Pair-wise 1 & Accomplishment & $\begin{array}{l}941 \mathrm{~ms} \\
(\mathrm{SD}=242)\end{array}$ & $\begin{array}{l}1032 \mathrm{~ms} \\
(\mathrm{SD}=289)\end{array}$ & $\mathrm{p}=$ & Perfective \\
\hline Pair-wise 2 & Activity & $\begin{array}{l}1211 \mathrm{~ms} \\
(\mathrm{SD}=379)\end{array}$ & $\begin{array}{l}1125 \mathrm{~ms} \\
(\mathrm{SD}=367)\end{array}$ & $\begin{array}{l}\mathrm{p} \\
.025\end{array}$ & $=\operatorname{Im}$ \\
\hline
\end{tabular}

In the case of accomplishment verbs, Madden and Zwaan (2003) earlier suggested that perfective utterances are processed faster because their inherent telicity (i.e. endpoint focus) allows the human mind to more rapidly converge on a mental representation of the event. However, what are the implications of imperfective facilitation for activity verbs? Yap et al. (2006) suggest that the tendency for imperfective constructions to focus on the internal stages of events perfectly matches the atelic nature of activity verbs. This then contributes to more rapid construction of mental models related to the event.

\section{Complex design (accomplishment verbs + activity verbs)}

Results from the more complex design, which simultaneously involved both activity verbs and accomplishment verbs, indicate that aspectual asymmetry is often sensitive to context. The results showed that, for activity verbs, imperfective gan 2 utterances (mean $=1096 \mathrm{~ms}, \mathrm{SD}=326$ ) were processed significantly faster than perfective $z o 2$ utterances (mean $=1239 \mathrm{~ms}, \mathrm{SD}=445$ ). The main effect of grammatical aspect was significant $(p=.011)$, and the interaction effect of lexical and grammatical aspect was also significant $(p=.017)$. A follow-up $t$-test showed that imperfective facilitation for activity verbs was statistically significant $(p<.001)$. However, for accomplishment verbs, there was no significant difference between the reaction times of perfective and imperfective utterances $(p=.884)$. Thus, whereas imperfective facilitation remained robust in complex environments involving activity and accomplishment verbs, perfective facilitation turned out to be rather fragile. Future studies will need to investigate the degree of robustness/fragility of perfective and imperfective facilitations in other types of complex environments (e.g. accomplishment and achievement verbs, with and without the presence of activity verbs).

\section{Why use both pair-wise and complex designs?}

The above results already justify the inclusion of both pair-wise and complex designs. With a pair-wise design, we can tease out the effect of grammatical aspect within a single verb 
class. For example, perfective facilitation was found with accomplishment verbs, while imperfective facilitation was found with activity verbs. The stability of these two types of facilitation (perfective and imperfective) can further be tested in complex environments that more closely resemble natural discourse processing in real time. Our more complex design reveals that when both accomplishment and activity verbs are used, perfective facilitation is fragile while imperfective facilitation remains robust. Yap et al. (2006) suggest that neighborhood density is a factor. A squishing effect is found when accomplishment verbs compete for mental resources with activity verbs. Arguably, a greater concentration of [+durative] features from both activities and accomplishments, as opposed to the previously balanced concentration of [+durative] and [+telic] features in an accomplishment only environment, undermines an inherent perfective advantage.

\section{Significance of reaction time studies for aspect studies}

Reaction time studies allow us to examine how aspectual asymmetries work in real-time. More specifically, they provide us with a means of empirically examining how grammatical aspect and lexical aspect interact with each other and how such interaction contributes to the dynamic representation of events in the human mind. Subtle effects such as neighborhood density can also be assessed through reaction time studies. Equally important, reaction time studies provide us with baseline information before we proceed with more sophisticated and high-cost ERP and fMRI testing.

\section{Acknowledgements}

We gratefully acknowledge funding from Direct Grant 2004-06 (\#2010255) from the Chinese University of Hong Kong and Competitive Earmarked Research Grant 2005-07 (\#2110122) from the Research Grants Council of Hong Kong. We also thank Lai Chim Chow, Irene Lam, Calvin Chan, Kimmee Lo, Edson Miyamoto, Him Cheung and participating schools for their valuable help in various ways in the studies.

\section{References}

Chan, Y.H., Yap, F.H., Shirai Y. and Matthews, S. 2004. A perfective-imperfective asymmetry in language processing: Evidence from Cantonese. Proc. 9th ICLL, 383-391. ASGIL, National Taiwan University, Taipei.

Comrie, B. 1976. Aspect. Cambridge, UK: Cambridge University Press.

Madden, C.J. and Zwaan, R.A. 2003. How does verb aspect constrain event representation? Memory \& Cognition, 31, 663-672.

Smith, C. 1991. The parameter of aspect. Dordrecht: Kluwer Academic Press.

Vendler, Z. 1967. Linguistics in Philosophy. Ithaca, NY: Cornell University Press.

Wong, F. 2006. Reaction time study on inherent lexical aspect asymmetry in Cantonese. Unpublished senior thesis in Linguistics. Department of Linguistics and Modern Languages, Chinese University of Hong Kong.

Yap, F. H., Kwan, W.M., Yiu, S.M., Chu, C.K., Wong, F., Matthews, S. and Shirai, Y. 2006. Aspectual asymmetries in the mental representation of events: significance of lexical aspect. Paper presented at the 28th Annual Conference of the Cognitive Science Society, Vancouver, July 26-29.

Yap, F. H., Inoue, Y., Shirai Y., Matthews, S., Wong, Y.W., and Chan, Y.H. (in press). Aspectual asymmetries in Japanese: Evidence from a reaction time study. Japanese/Korean Linguistics, vol. 14. Stanford, CSLI. 